ARTICLE III-Dues and Assessments, Section 2-Dues Rates

a. Regular Members. The annual dues of regular members of the Association shall be three hundred fifteen dollars (\$315) THREE HUNDRED NINETY DOLLARS (\$390), effective in the 1989/90 fiscal years. Forty dollars $(\$ 40)$ of the annual dues of regular members shall be placed in a restricted, interest bearing account for a period of ten (10) years, identified as the "Endowment for Osteopathic Research," dedicated to the furtherance of research in the profession. Ninety (90) percent of the interest earnings from this account may be utilized and the remainder of the interest accrues to the corpus of the fund. The available earnings shall be utilized by the Bureau of Research of this Association to support the development of qualified clinical investigators in osteopathic philosophy, principles and practice and to support targeted research on osteopathic philosophy, principles and practice.

Explanatory Statement: Membership dues have not been increased since 1980 for operating funding, therefore the Board of Trustees is recommending an increase of $\$ 75$ ( $\$ 315$ to $\$ 390$ ), which includes $\$ 40$ for research.

(New Section)

H. ASSOCIATE MEMBERS. THE ANNUAL DUES OF ASSOCIATE MEMBERS OF THE ASSOCIATION SHALL BE SEVENTY-FIVE DOLLARS (\$75).

\title{
Proposed Amendment to the AOA Constitution
}

In July, 1989, the House of Delegates adopted the following proposed amendments to the Constitution of the American Osteopathic Association to be submitted to a vote pursuant to the terms of the Constitution and Bylaws at the 1990 Annual Meeting:

(old material in italics; new material in capitals)

Article VIII-Board of Trustees and Executive Committee Section 1-Board of Trustees.

The Board of Trustees of this Association shall consist of the President, President-elect, the Past Presidents for the preceding two years, First Vice President, Second Vice President, Third Vice President, and of fifteen EIGHTEEN other members, five SIX of whom shall be elected annually by the House of Delegates to serve for three years. The Board shall be the administrative and executive body of the Association and perform such other duties as are provided by the Bylaws.

Explanatory Statement: The Board of Trustees' intention in submitting this amendment is to facilitate representation of additional states to the Board. 



\section{The new starting dose... for your newly diagnosed mild to moderate hypertensives}

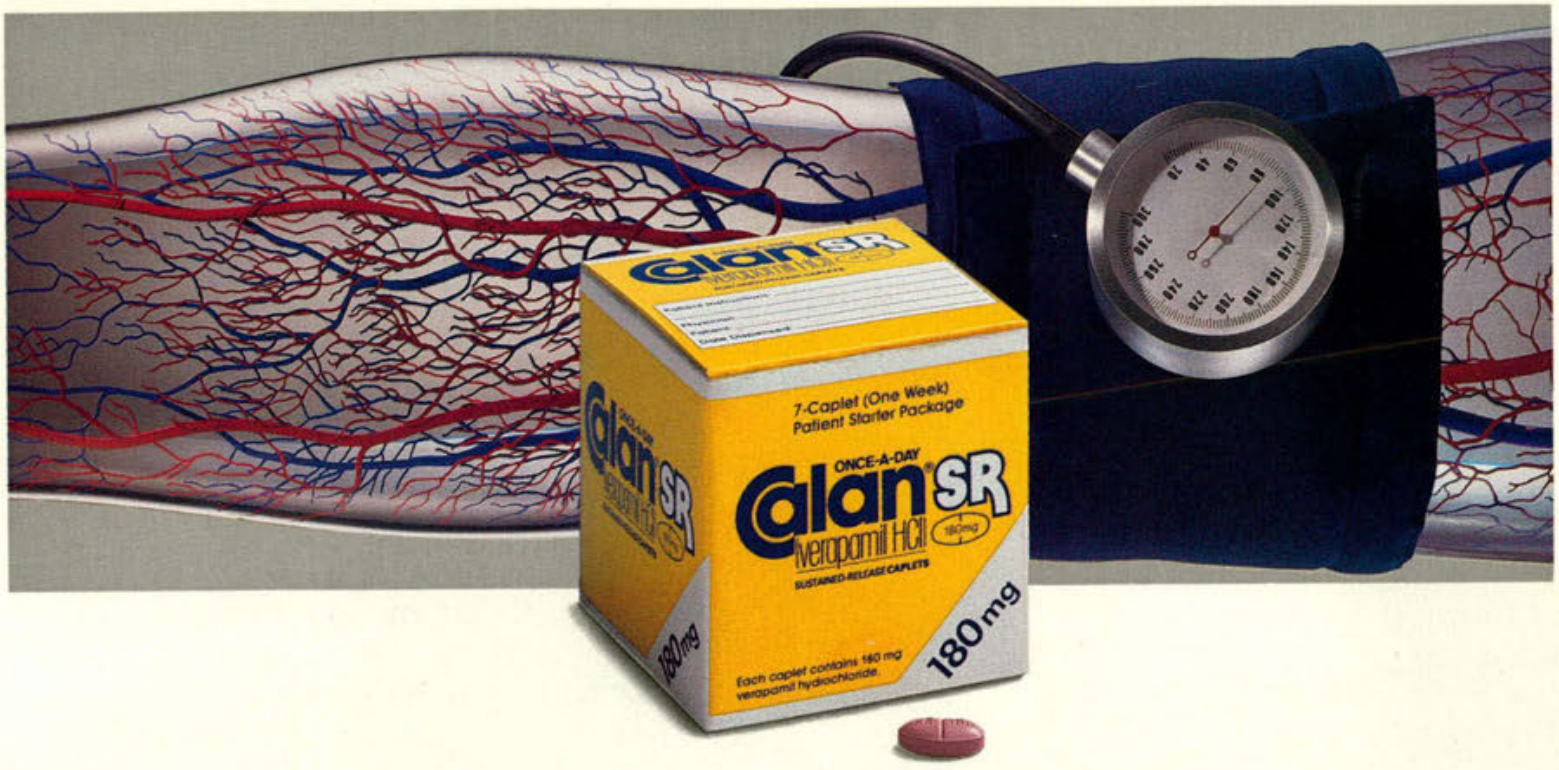

\section{NEW RECOMMENDED STARTING DOSE... CALAN SR $180 \mathrm{mg}$ q.d*}

Single-agent success with Calan SR

- $80 \%$ single-agent success rate ${ }^{\dagger l-6}$

- Effective regardless of age ${ }^{\neq 1-6}$ or race ${ }^{2}$

- No adverse effect on lipid profile ${ }^{7}$

- Not associated with adverse effects on serum glucose in diabetic hypertensive patients $^{8}$

- Not characteristically associated with diminished cardiac output ${ }^{9}$

- Not associated with adverse renal effects 9

- No adverse effect on magnesium and potassium levels

- Backed by the Searle Patient Promise Program

Constipation, which can be easily managed in most patients, is the most frequently reported side effect of Calan SR.

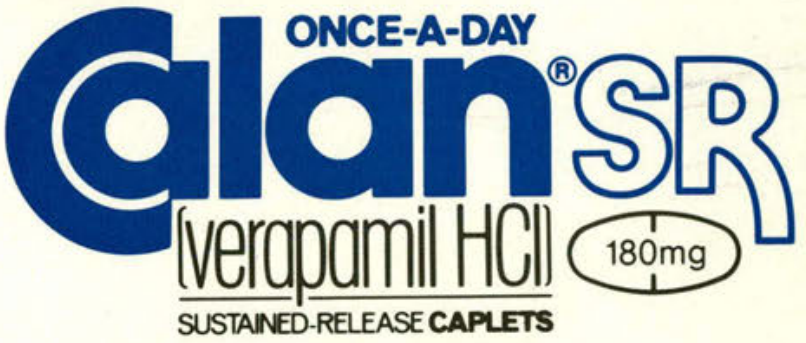

New recommended initial dose for mild to moderate hypertension

- Lower initial doses of $120 \mathrm{mg}$ a day may be warranted in patients who may have an increased response to verapamil (eg, the elderly or small people).

tDefined by the single-agent success rate of patients achieving goal $\mathrm{BP}$ reduction in clinical studies 10 of over 4,000 adult patients, employing varied dosage titration schedules up to $360 \mathrm{mg}$ or $480 \mathrm{mg}$ daily.

'For adult hypertensives only. 


\section{For the newly diagnosed hypertensive...}

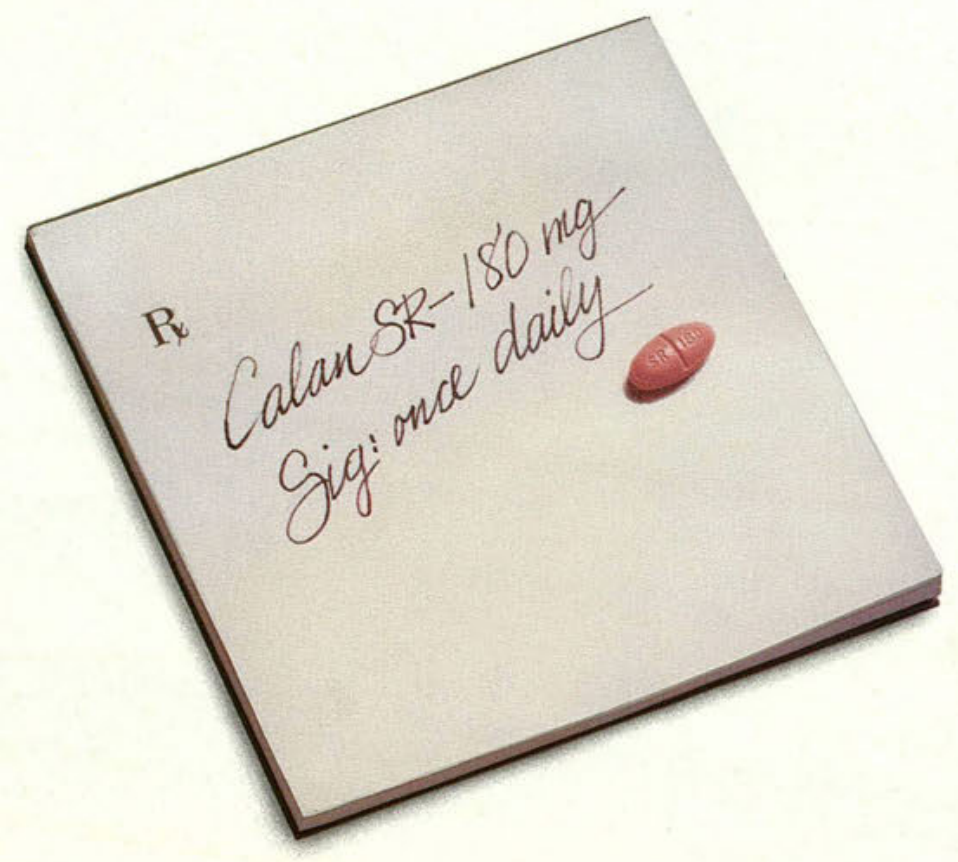

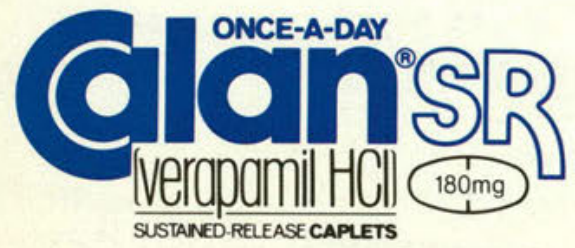

\section{BRIEF SUMMARY}

Contraindications: Severe LV dysfunction (see Warnings), hypotension (systolic pressure $<90 \mathrm{~mm} \mathrm{Hg}$ ) or cardiogenic shock, sick sinus syndrome (if no pacemaker is present), 2ndor 3rd-degree AV block (if no pacemaker is present), atrial flutter/fibrillation with an accessory bypass tract (eg, WPW or LGL syndromes), hypersensitivity to verapamil.

Warnings: Verapamil should be avoided in patients with severe LV dysfunction (eg, ejection fraction $<30 \%$ ) or moderate to severe symptoms of cardiac failure and in patients with any degree of ventricular dysfunction if they are receiving a beta-blocker. Control milder heart failure with optimum digitalization and/or diuretics before Calan SR is used. Verapamil may occasionally produce hypotension. Elevations of liver enzymes have been reported. Several cases have been demonstrated to be produced by verapamil. Periodic monitoring of liver function in patients on verapamil is prudent. Some patients with paroxysmal and/or chronic atrial flutter/fibrillation and an accessory AV pathway (eg. WPW or LGL syndromes) have developed an increased antegrade conduction across the accessory pathway bypassing the AV node, producing a very rapid ventricular response or ventricular fibrillation after receiving I.V. verapamil (or digitalis). Because of this risk, oral verapamil is contraindicated in such patients. AV block may occur (2nd- and 3rd-degree, $0.8 \%$ ). Development of marked 1stdegree block or progression to 2 nd- or 3 rd-degree block requires reduction in dosage or, rarely, discontinuation and institution of appropriate therapy. Sinus bradycardia, 2nd-degree AV block, sinus arrest, pulmonary edema and/or severe hypotension were seen in some critically ill patients with hypertrophic cardiomyopathy who were treated with verapamil.

Precautions: Verapamil should be given cautiously to patients with impaired hepatic function (in severe dysfunction use about $30 \%$ of the normal dose) or impaired renal function, and patients should be monitored for abnormal prolongation of the PR interval or other signs of overdosage. Verapamil may decrease neuromuscular transmission in patients with Duchenne's muscular dystrophy and may prolong recovery from the neuromuscular blocking agent vecuronium. It may be necessary to decrease verapamil dosage in patients with attenuated neuromuscular transmission. Combined therapy with beta-adrenergic blockers and verapamil may result in additive negative effects on heart rate, atrioventricular conduction and/or cardiac contractility; there have been reports of excessive bradycardia and AV block, including complete heart block. The risks of such combined therapy may outweigh the benefits. The combination should be used only with caution and close monitoring. Decreased metoprolol clearance may occur with combined use. Chronic verapamil treatment can increase serum digoxin levels by $50 \%$ to $75 \%$ during the first week of therapy, which can result in digitalis toxicity. In patients with hepatic cirrhosis, verapamil may reduce total body clearance and extrarenal clearance of digitoxin. The digoxin dose should be reduced when verapamil is given, and the patient carefully monitored. Verapamil will usually have an additive effect in patients receiving blood-pressure-lowering agents. Disopyramide should not be given within 48 hours before or 24 hours after verapamil administration. Concomitant use of flecainide and verapamil may have additive effects on myocardial contractility, AV conduction, and repolarization. Combined verapamil and quinidine therapy in patients with hypertrophic cardiomyopathy should be avoided, since significant hypotension may result. Concomitant use of lithium and verapamil may result in a lowering of serum lithium levels or increased sensitivity to lithium. Patients receiving both drugs must be monitored carefully. Verapamil may increase carbamazepine concentrations during combined use. Rifampin may reduce verapamil bioavailability. Phenobarbital may increase verapamil clearance. Verapamil may increase serum levels of cyclosporin. Concomitant use of inhalation anesthetics and calcium antagonists needs careful titration to avoid excessive cardiovascular depression. Verapamil may potentiate the activity of neuromuscular blocking agents (curare-like and depolarizing); dosage reduction may be required. Adequate animal carcinogenicity studies have not been performed. One study in rats did not suggest a tumorigenic potential, and verapamil was not mutagenic in the Ames test. Pregnancy Category C. There are no adequate and well-controlled studies in pregnant women. This drug should be used during pregnancy, labor, and delivery only if clearly needed. Verapamil is excreted in breast milk; therefore, nursing should be discontinued during verapamil use.

Adverse Reactions: Constipation (7.3\%), dizziness (3.3\%), nausea (2.7\%), hypotension $(2.5 \%)$, headache $(2.2 \%)$, edema $(1.9 \%)$, CHF, pulmonary edema $(1.8 \%)$, fatigue $(1.7 \%)$, dyspnea (1.4\%), bradycardia: HR $<50 /$ min $(1.4 \%)$, AV block: total $1^{\circ}, 2^{\circ}, 3^{\circ}(1.2 \%), 2^{\circ}$ and $3^{\circ}(0.8 \%)$, rash $(1.2 \%)$, flushing $(0.6 \%)$, elevated liver enzymes. The following reactions, reported in $1.0 \%$ or less of patients, occurred under conditions where a causal relationship is uncertain: angina pectoris, atrioventricular dissociation, chest pain, claudication, myocardial infarction, palpitations, purpura (vasculitis), syncope, diarrhea, dry mouth, gastrointestinal distress, gingival hyperplasia, ecchymosis or bruising, cerebrovascular accident, confusion, equilibrium disorders, insomnia, muscle cramps, paresthesia, psychotic symptoms, shakiness, somnolence, arthralgia and rash, exanthema, hair loss, hyperkeratosis, macules, sweating, urticaria, Stevens-Johnson syndrome, erythema multiforme, blurred vision, gynecomastia, increased urination, spotty menstruation, impotence. $12 / 21 / 89 \cdot P 90-W 198 \mathrm{~V}$

References: 1. Reinfrank J, Eckardt A, Schneider G, et al: Long-term efficacy and safety of verapamil SR $240 \mathrm{mg}$ in hypertension. Acta Therapeutica 1989:15:221-235. 2. Saunders E, Weir MR, Kong BW, et al: A comparison of the efficacy and safety of a beta blocker, calcium channel blocker, and converting enzyme inhibitor in hypertensive blacks. Arch Intern Med (accepted for publication). 3. Speders S, Sosna J, Schumacher A, et al: Efficacy and safety of verapamil SR $240 \mathrm{mg}$ in essential hypertension: Results of a multicentric phase IV study. J Cardiovasc Pharmacol 1989;13(suppl 4):S47. S49. 4. Henry JA, Chester PC, Latham AN: Sustained-release verapamil or atenolol in essential hypertension. J Drug Dev 1988;1:69-75. 5. Midtbo KA, Hals O, Lauve O: A new sustained-release formulation of verapamil in the treatment of hypertension. J Clin Hypertens 1986;3:125S-132S. 6. Bochsler JA, Simmons RL, Ward PJ, et al: Verapamil SR and propranolol LA: A comparison of efficacy and side effects in the treatment of mild to moderate hypertension. $J$ Hum Hypertens 1988; 305-310. 7. Midtbø K, Lauve O, Hals O: No metabolic side effects of long-term treatment with verapamil in hypertension. Angiology 1988;39:1025-1029. 8. Cruickshank JK, Anderson NMcF, Wodsworth J, et al: Treating hypertensive diabetics: A comparison of verapamil and metoprolol in black and white patients. J Cardiovasc Pharmacol 1987:10(suppl 10):S85-S86. 9. Schmieder RE, Messerli FH, Garavaglia GE, et al: Cardiovascular effects of verapamil in patients with essential hypertension. Circulation 1987:75:1030-1036.

A90-W259T

Address medical inquiries to: G.D. Searle \& Co

Medical \& Scientific

Information Department 
